\title{
Norepinephrine-induced hypertension dilates vasospastic basilar artery after subarachnoid haemorrhage in rabbits
}

\author{
Volker Neuschmelting • Ali-Reza Fathi • Eveline Teresa Hidalgo Staub • \\ Serge Marbacher • Gerhard Schroth • Jukka Takala • Stephan M. Jakob • \\ Javier Fandino
}

Received: 16 June 2008 / Accepted: 14 October 2008 / Published online: 3 April 2009

(C) Springer-Verlag 2009

\begin{abstract}
Background Vasopressor-induced hypertension is routinely indicated for prevention and treatment of cerebral vasospasm (CVS) after subarachnoid haemorrhage (SAH). Mechanisms underlying patients' clinical improvement during vasopressor-induced hypertension remain incompletely understood. The aim of this study was to evaluate angiographic effects of normovolaemic Norepinephrine (NE)-induced hypertension therapy on the rabbit basilar artery (BA) after SAH.

Methods Cerebral vasospasm was induced using the onehaemorrhage rabbit model; sham-operated animals served as controls. Five days later the animals underwent follow-up angiography prior to and during NE-induced hypertension.
\end{abstract}

Volker Neuschmelting and Ali-Reza Fathi contributed equally to the study.

V. Neuschmelting $\cdot$ A.-R. Fathi $\cdot$ S. Marbacher $\cdot$ J. Takala $\cdot$

S. M. Jakob $\cdot$ J. Fandino

Department of Intensive Care Medicine,

Bern University Hospital and University of Bern,

Bern, Switzerland

V. Neuschmelting $\cdot$ A.-R. Fathi $\cdot$ E. T. Hidalgo Staub $\cdot$

S. Marbacher $\cdot$ J. Fandino

Department of Neurosurgery,

Bern University Hospital and University of Bern,

Bern, Switzerland

G. Schroth

Institute of Neuroradiology,

Bern University Hospital and University of Bern,

Bern, Switzerland

A.-R. Fathi $(\bowtie)$

Departments of Neurosurgery and Intensive Care Medicine,

University Hospital Berne,

3010 Berne, Switzerland

e-mail: AR.Fathi@gmx.net
Changes in diameter of the BA were digitally calculated in mean $\mu \mathrm{m} \pm \mathrm{SEM}$ (standard error of mean).

Findings Significant CVS of $14.2 \%$ was documented in the BA of the SAH animals on day 5 compared to the baseline angiogram on day $0(n=12, p<0.01)$, whereas the BA of the control animals remained statistically unchanged $(n=12, p>0.05)$. During systemic administration of NE, mean arterial pressure increased from 70.0土 $1.9 \mathrm{mmHg}$ to $136.0 \pm 2.1 \mathrm{mmHg}$ in the $\mathrm{SAH}$ group $(n=12, p<0.001)$ and from $72.0 \pm 3.1$ to $137.8 \pm 1.3$ in the control group $(n=12, p<0.001)$. On day 5 after SAH, a significant dilatation of the $\mathrm{BA}$ in response to norepinephrine could be demonstrated in both groups. The diameter of the BA in the SAH group increased from $640.5 \pm 17.5 \mu \mathrm{m}$ to $722.5 \pm 23.7 \mu \mathrm{m}(n=12, p<0.05$; $)$. In the control group the diameter increased from $716.8 \pm 15.5$ $\mu \mathrm{m}$ to $779.9 \pm 24.1 \mu \mathrm{m}(n=12, p<0.05)$.

Conclusion This study demonstrated that NE-induced hypertension causes angiographic dilatation of the BA in the SAH rabbit model. Based on these observations, it can be hypothesised that clinical improvement during vasopressor-induced hypertension therapy after SAH might be explained with cerebral vasodilatation mechanisms that lead to improvement of cerebral blood flow.

Keywords Subarachnoid haemorrhage - Cerebral vasospasm · Triple-H therapy · Induced hypertension . Norepinephrine

$\begin{array}{ll}\text { Abbreviations } \\ \text { CVS } & \text { Cerebral vasospasm } \\ \text { SAH } & \text { Subarachnoid haemorrhage } \\ \text { NE } & \text { Norepinephrine } \\ \text { BA } & \text { Basilar artery } \\ \text { SEM } & \text { Standard error of the mean } \\ \text { MAP } & \text { Mean arterial pressure }\end{array}$


DIND Delayed ischemic neurological deficits

CBF Cerebral blood flow

DSA Digital subtraction angiography

$\mathrm{HHH}$ Haemodilution, hypervolaemia, induced hypertension

\section{Introduction}

Delayed cerebral vasospasm (CVS) is considered the principal cause of high morbidity and mortality in patients undergoing treatment of subarachnoid haemorrhage [27], leading to delayed ischaemic neurological deficits (DIND), permanent neurological damage and death. It mainly transiently occurs 4-8 days after onset of SAH [5, 9, 14, 24]. Despite decades of research, the pathogenesis of CVS remains unclear [22].

Progress has been made in the management of CVS. Routine protocols combine early surgery with systemic administration of the calcium channel antagonist, nimodipine, and hyperdynamic therapy. As a result, the mortality and morbidity due to CVS have been reduced to $5-10 \%$, compared to about $20 \%$ rates in the early 1980s [24].

Hyperdynamic therapy consists of haemodilution, hypervolaemia and induced hypertension $(\mathrm{HHH})$, and is routinely administered despite some controversy [12, 14, 19, 24, 28]. The efficacy of haemodilution and hypervolaemia in particular has been seriously questioned lately $[13,17,23$, 24]. A relative risk of extracranial complications has been reported, and includes pulmonary oedema, hyponatraemia and congestive heart failure, to mention the most common. Induced hypertension, although associated with the possible risk of rebleeding from the aneurysm, has been evaluated as being safe [6, 16]. Vasopressors such as norepinephrine (NE) and phenylephrine are most commonly used clinically to induce hypertension during $\mathrm{HHH}$ therapy after $\mathrm{SAH}$ [14]. An improvement in patients' cerebral blood flow (CBF) and, thus, cerebral perfusion and clinical outcome has been documented in several studies $[1,8,10,17,18$, 23]. However, the mechanism underlying patients' enhanced clinical status remains incompletely understood. The aim of this study was to evaluate angiographic effects of normovolaemic NE-induced hypertension therapy on the rabbit BA after SAH.

\section{Materials and methods}

\section{Study design}

The protocol of this study was reviewed and approved by the Swiss Institutional Animal Care and Use Committee as meeting the Swiss guidelines for laboratory animal use (approval \#16/06). Twenty-four adult New Zealand White rabbits of either sex weighing $2.6-3.6 \mathrm{~kg}$ were randomly assigned to two experimental groups (12 animals each). One of these groups underwent experimental SAH on day 0 , while the other served as a sham-operated control. All surgical procedures were performed under sterile conditions.

\section{Angiography}

After induction of general anaesthesia by intramuscular administration of ketamine $(30 \mathrm{mg} / \mathrm{kg})$ and xylazine (6 $\mathrm{mg} / \mathrm{kg}$ ), digital subtraction angiography (DSA) was performed on day 0 prior to SAH and on day 5 post SAH and sham-operation, respectively, in accordance with our protocol recently reported [15]. In brief, the rabbits' left (day 0) or right (day 5) subclavian artery was microsurgically cannulated using a catheter that was fixed distal to the vertebral branch. Subsequently, images of the vertebro-basilar system were obtained by rapid sequential DSA using intra-arterial bolus injection of non-ionic iopamidol $(0.6 \mathrm{ml} / \mathrm{kg})$ as contrast agent. Meanwhile, the arterial blood gas status was analysed to monitor ventilation parameters. The average diameter of the BA was digitally

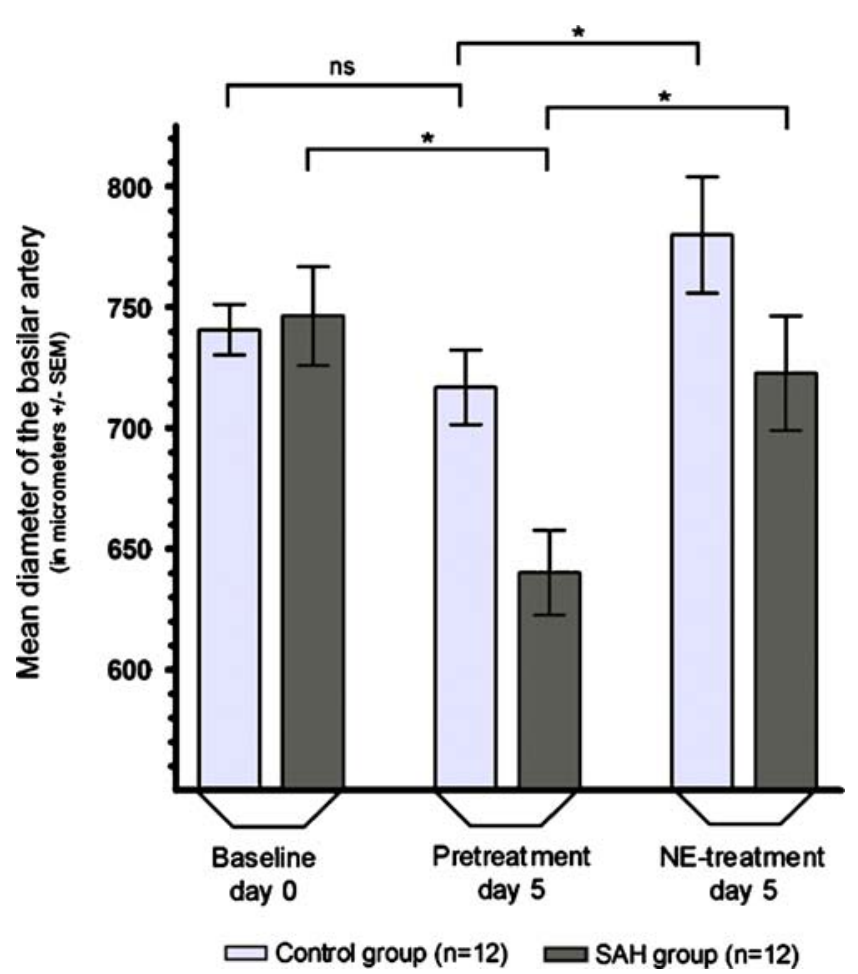

Fig. 1 Box plot showing the absolute change of the BA in diameter in SAH animals compared to controls (in $\mu \mathrm{m} \pm$ SEM): Baseline angiography on day 0 vs. pre-treatment follow up on day 5 vs. angiography during NE-induced hypertension on day $5 .\left({ }^{*} p<0.05 ; n s\right.$ non-significant) 
Table 1 The effect of NE-induced hypertension on the rabbits' BA diameter in summary

\begin{tabular}{|c|c|c|c|c|c|c|c|c|}
\hline \multirow[t]{2}{*}{ Exp group } & \multirow[t]{2}{*}{$\mathrm{n}$} & \multirow[t]{2}{*}{ State of treatment } & \multirow[t]{2}{*}{ BA diameter in $\mu \mathrm{m}$ (mean \pm SEM) } & \multicolumn{2}{|c|}{$\begin{array}{l}\Delta \text { BA diameter } \\
\text { to previous state }\end{array}$} & \multirow[t]{2}{*}{ MAP in mmHg (mean \pm SEM) } & \multicolumn{2}{|c|}{$\begin{array}{l}\Delta \text { mean MAP to } \\
\text { previous state }\end{array}$} \\
\hline & & & & in $\mu \mathrm{m}$ & in $\%$ & & in $\mathrm{mmHg}$ & in $\%$ \\
\hline \multirow[t]{3}{*}{ control } & 12 & baseline-day 0 & $740.6 \pm 10.4$ & & & $73.9 \pm 2.8$ & & \\
\hline & & pretreatment-day 5 & $716.8 \pm 15.5$ & 23.8 & 3.2 & $72.0 \pm 3.1$ & 1.9 & 2.5 \\
\hline & & NE-treatment-day 5 & $779.9 \pm 24.1$ & $63.1 *$ & 8.9 & $137.8 \pm 1.3$ & $65.8 * * *$ & 91.4 \\
\hline \multirow[t]{3}{*}{ SAH } & 12 & baseline-day 0 & $746.2 \pm 20.5$ & & & $73.7 \pm 2.1$ & & \\
\hline & & pretreatment-day 5 & $640.5 \pm 17.5$ & $105.7 * *$ & 14.2 & $70.0 \pm 1.9$ & 3.7 & 5.0 \\
\hline & & NE-treatment-day 5 & $722.5 \pm 23.7$ & $82.0 *$ & 12.9 & $136.0 \pm 2.1$ & $66.0 * * *$ & 94.3 \\
\hline
\end{tabular}

$\left({ }^{*} p<0.05,{ }^{* *} p<0.01, * * * p<0.001\right)$

calculated in $\mu \mathrm{m}$ using the automatic measurement tool of the ImagePro Discovery ${ }^{\circledR}$ analysis software (MediaCybernetics, Bethesda, MD, USA).

\section{Cerebral vasospasm model}

Following baseline DSA on day 0 , the rabbits underwent the one-haemorrhage SAH rabbit model, as reported earlier by our group [4, 15]. Briefly, after draining of $1.0 \mathrm{ml}$ cerebrospinal fluid, an equal amount of unheparinised autologous arterial blood was injected into the cerebro-medullary cistern under microscopic view to imitate SAH in order to induce CVS. An equal amount of isotonic saline solution was used instead in controls. Postsurgical pain relief was managed by subcutaneous administration of buprenorphine $(0.1-0.2 \mathrm{mg} / \mathrm{kg})$ for up to $36 \mathrm{~h}$ after SAH.

\section{Induction of hypertension}

After performance of pre-treatment follow-up DSA on day 5, peripheral hypertension was induced by continuous central arterial administration of NE $\left(2.3-4.0 \mu \mathrm{g}_{*} \mathrm{~min}_{*}{ }^{-1} \mathrm{~kg}^{-1}\right)$ in dose-dependency to monitored blood pressure, the mean arterial pressure (MAP) in particular. Under constant conditions, a second follow-up DSA was performed to register any change of the BA diameter during peripheral hypertension.

\section{Drugs}

The following drugs were used: buprenorphinum (Temgesic $^{\circledR} 0.3 \mathrm{mg} / \mathrm{ml}$, Essex Chemie, Lucerne, Switzerland); iopamidol (Iopamiro ${ }^{\circledR} 300 \mathrm{mg} / \mathrm{ml}$, Bracco, Milano, Italy); isoflurane (Forene ${ }^{\circledR}$ 99\%, Abbott Laboratories, Abbott Park, IL, USA); ketamine $\mathrm{HCl}$ (Ketalar ${ }^{\circledR} 50 \mathrm{mg} / \mathrm{ml}$, Pfizer AG, Zurich, Switzerland); norepinephrine (Noradrenalin Bichsel ${ }^{\circledR}$, Bichsel, Interlaken, Switzerland); sodium thio- pental (Pentothal ${ }^{\circledR} 25 \mathrm{mg} / \mathrm{ml}$, Abbott Laboratories, Abbott Park, IL, USA); and xylazine $\mathrm{HCl}$ (Xylapan ${ }^{\circledR} 20 \mathrm{mg} / \mathrm{ml}$, Vetoquinol AG, Bern, Switzerland).

\section{Statistical methods}

Values were expressed as a mean in each group $\pm \operatorname{SEM}(n=$ number of animals). Statistical significance between 2 means and multiple means was determined by parametric One-way-ANOVA and Bonferroni's multiple comparisons post-testing, respectively. Statistical significance was con-

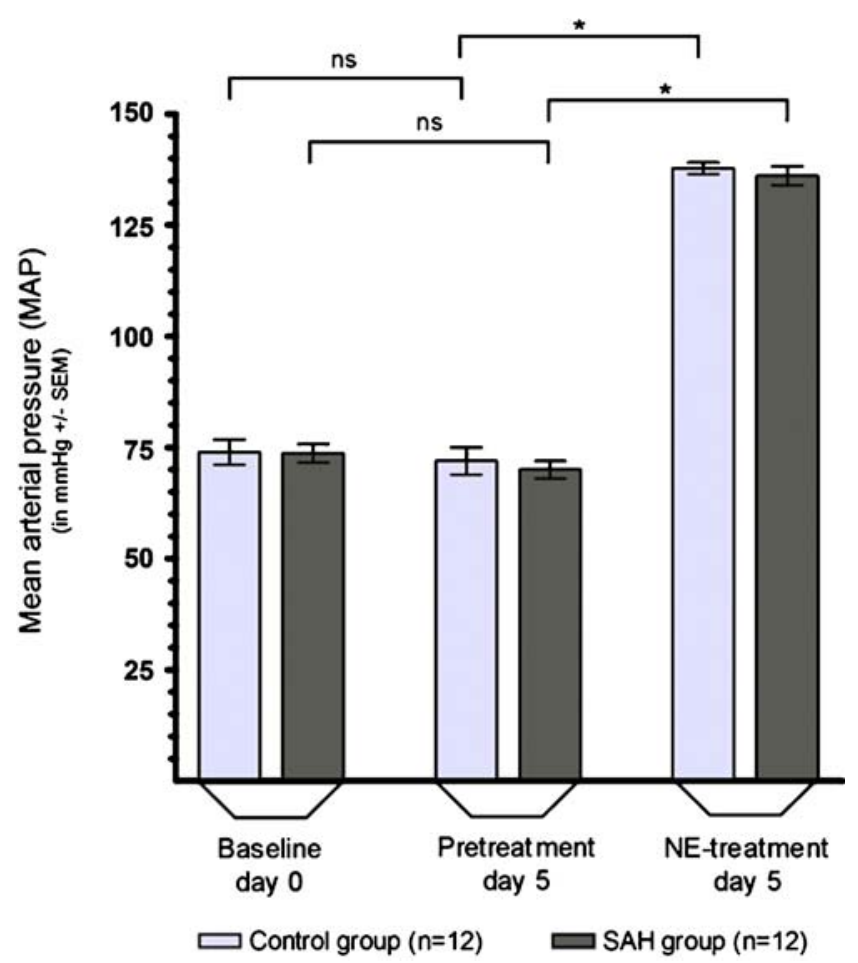

Fig. 2 Box plot showing the absolute MAP changes of the SAH group compared to controls (in $\mathrm{mmHg} \pm \mathrm{SEM}$ ): During baseline angiography on day 0 vs. pre-treatment follow up on day 5 vs. NEinduced hypertension on day 5 . $\left({ }^{*} p<0.05 ; n s\right.$ non-significant) 


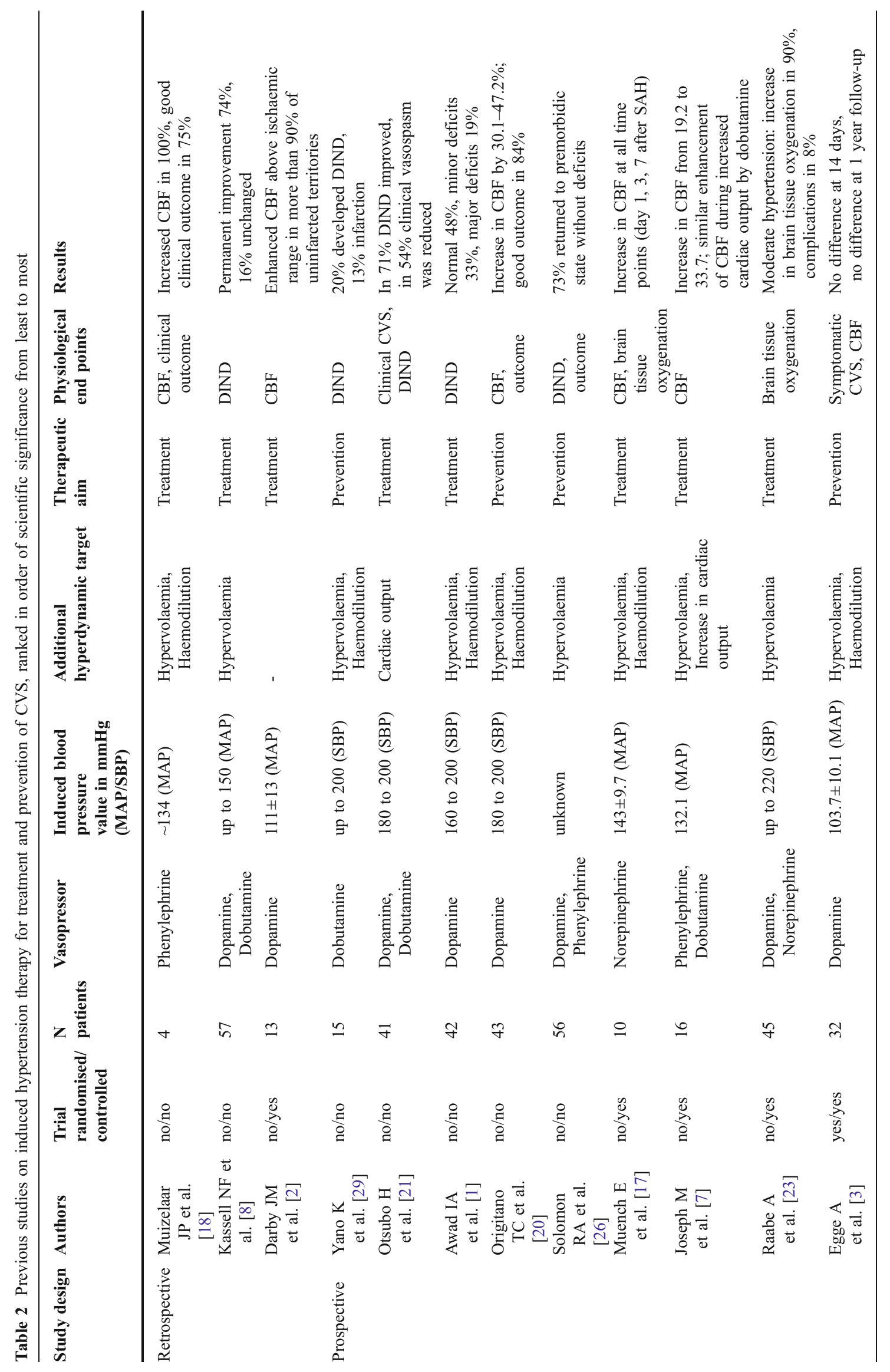


sidered if the P-value was less than $0.05(p<0.05)$ in context of the $95 \%$ confidence intervals of the difference examined $(95 \% \mathrm{CI}$ of diff).

\section{Results}

Arteriographic changes of the vessel diameter

On day 5 after SAH the diameter of the BA was significantly narrowed by $14.2 \pm 2.8 \%$, to $640.5 \pm 17.5 \mu \mathrm{m}$ in pre-treatment state compared to the baseline angiogram $(746.2 \pm 20.5 \mu \mathrm{m})$ on day $0(n=12, p<0.01,95 \%$ CI of diff: $37.4-175.0 \mu \mathrm{m})$. In contrast, the BA diameter in controls was on average $740.6 \pm$ $10.4 \mu \mathrm{m}$ wide on the baseline angiogram on day 0 and remained statistically unchanged to the pre-treatment state on day $5(716.8 \pm 15.5 \mu \mathrm{m}) \quad(n=12, p>0.05,95 \%$ CI of diff: $-34.7 \mu \mathrm{m}$ to $82.3 \mu \mathrm{m}$ ). The SAH and control groups were, thus, significantly different from each other in diameter five days after the induction of SAH and the sham operation, respectively, prior to the administration of $\mathrm{NE}$ ( $p<0.05,95 \%$ CI of diff: $10.0-143.5 \mu \mathrm{m}$ ) (Fig. 1).

Continuous administration of NE on day 5 in the SAH group caused significant arteriographic dilation of the spastic vessel by $12.97 \%$ to $722.5 \pm 23.7 \mu \mathrm{m}$ in diameter $(n=12$, $p<0.05,95 \%$ CI of diff: $13.8-150.2 \mu \mathrm{m})$. In controls, the administered NE significantly dilated the BA by $8.86 \%$, to $779.9 \pm 24.1 \mu \mathrm{m}$ in relation to $716.8 \pm 15.5 \mu \mathrm{m}$ in the pretreatment state $(n=12, p<0.05,95 \%$ CI of diff: $4.6-121.6 \mu \mathrm{m})$. During continuous administration of NE on day 5 , the groups did not statistically differ in BA diameter ( $p>0.05,95 \%$ CI of diff: $-9.4 \mu \mathrm{m}$ to $124.1 \mu \mathrm{m}$ ) (Fig. 1). The relative dilating effect on the $\mathrm{BA}$ diameter in the $\mathrm{SAH}$ group $(+12.97 \pm 2.52 \%)$ was also statistically insignificant in comparison to the relative effect of NE-induced hypertension detected in the BA of controls $(+8.86 \pm 2.66 \%, n=12, p>$ $0.05,95 \%$ CI of diff: -3.67 to 11.8 ) (Table 1 ).

The initial blood gas parameters, such as $\mathrm{pO}_{2}$ $(54.8 \pm 1.7 \mathrm{mmHg}), \mathrm{pCO}_{2}(51.9 \pm 1.2 \mathrm{mmHg})$ and $\mathrm{pH}$ ( $7.38 \pm 0.01)$, did not change compared to the values monitored during follow-up angiography on day 5 in both the SAH $(p>0.05)$ and control groups $(p>0.05)$, and did not statistically differ between the two groups $(p>0.05)$.

\section{Assessed changes of arterial blood pressure}

During the baseline angiography on day 0 , the MAP of the SAH group was at a level of $73.7 \pm 2.1 \mathrm{mmHg}(n=12)$. It remained statistically unchanged in comparison to its MAP pre-treatment assessment 5 days later $(70.0 \pm 1.9 \mathrm{mmHg}, p>$ $0.05,95 \%$ CI of diff: -3.2 to $10.5 \mathrm{mmHg}$ ). Correspondingly, controls showed similar MAP values. They started at a level of $73.9 \pm 2.8 \mathrm{mmHg}$ at baseline on day 0 and remained statistically unchanged at $72.0 \pm 3.1 \mathrm{mmHg}$ in pre-treatment state on day 5 ( $n=12, p>0.05,95 \% \mathrm{CI}$ of diff: $-6.4 \mathrm{mmHg}$ to $10.3 \mathrm{mmHg}$ ). In $\mathrm{SAH}$ animals, continuous administration of NE on day 5 induced a highly significant increase in MAP to $136.0 \pm 2.1 \mathrm{mmHg}(n=12, p<0.001,95 \% \mathrm{CI}$ of diff: $59.2-72.9 \mathrm{mmHg}$ ) compared to their pre-treatment state. Corresponding constant hypertension at a MAP level of $137.8 \pm 1.3 \mathrm{mmHg}$ was achieved in controls $(n=12)$; it also showed a highly significant MAP rise compared to the time prior to the administration of NE on day $5(p<0.001,95 \% \mathrm{CI}$ of diff: $57.5-74.1 \mathrm{mmHg}$ ) (Fig. 2).

The MAP level of the SAH group was similar to the level in controls throughout the pre-NE state within the 5 days the experiment lasted $(p>0.05)$. There was also no significant difference detected in the extent of induced hypertension between those two groups ( $n=12$ each, $p>$ $0.05,95 \%$ CI of diff: $-6.2 \mathrm{mmHg}$ to $9.7 \mathrm{mmHg}$ ) (Table 1 ).

\section{Discussion}

Since it was first described in the 1970s, several studies have focused on the efficacy of vasopressor-induced hypertension therapy after SAH. The potency in both

$$
\begin{aligned}
& \text { The laminar flow through a pipe is } \\
& \text { physically described by the Hagen-Poiseuille law. } \\
& Q=\frac{\Delta P \pi r^{4}}{8 L \eta}=c \frac{\Delta P r^{4}}{\eta} \\
& \uparrow Q=c \frac{(\uparrow \Delta P) r^{4}}{\eta}
\end{aligned}
$$

Our results, however, suggest the increased CBF observed in previous studies during incluced hypertension to be additionally caused by a dilative effect on the vessel diameter: Remarkable to mention is again its proportion to the CBF to the fourth power. Thus, small difference in diameter results in big difference in CBF.

$$
\uparrow Q=c \frac{(\uparrow \Delta P)(\uparrow r)^{4}}{\eta}
$$

Fig. 3 The Hagen-Poiseuille law of laminar flow is extrapolated to $\mathrm{CBF}$ and put in context to our results 
prevention and treatment of CVS has been examined. The efficacy of the therapy as a preventive approach remains controversial due to conflicting data reported. While some authors observed in non-controlled, non-randomised trials that induced hypertension as part of $\mathrm{HHH}$ was beneficial in preventing CVS and DIND [20, 26, 29], Egge et al. was not able to repeat these finding in his prospective, controlled and randomised setting [3]. The preventive efficacy is thus considered questionable, with the need of induced hypertension therapy having been examined separately in a large, randomised, controlled clinical trial [14, 28].

However, vasopressor-induced hypertension is used routinely in the clinic and is - in contrast to the preventive approach-recommended for the treatment of clinical or angiographic CVS which is resistant to nimodipine [14, 24]. Support is based on several studies: three of them included additional hyperdynamic targets as part of $\mathrm{HHH}$ and concluded that there were benefits in the treatment of CVS in terms of enhancing CBF or improving clinical outcome $[1,8,18]$. Another five studies examined induced hypertension therapy separately from the haemodilutional and hypervolaemic approach and came to similar conclusions regarding its efficacy in terms of cerebral perfusion or neurological deficits (Table 2) [2, 7, 17, 21, 23]. In fact, hypertension has been demonstrated to be superior to hypervolaemia in its effectiveness $[7,17,23]$. Due to the lack of large, blinded, randomised and controlled trials on its efficacy in treating CVS, however, its scientific level of evidence has not exceeded level II.

The causes underlying the clinical observation of enhanced $\mathrm{CBF}$ and improved clinical outcome by vasopressor-induced hypertension in patients suffering from CVS have remained uncertain. During CVS the main cerebral vasculature resistance is shifted from the small arterioles to the narrowed major cerebral vessels. The vascular capacity of auto-regulation is impaired in the cerebral branches supplied by the narrowed arteries [11, 25]. CBF through the narrowed vessels thus becomes the limiting factor for the cerebral perfusion. Based on the Hagen-Poiseuille law of laminar flow, CBF may be manipulated by blood pressure gradient, vessel diameter and blood viscosity. So far, the enhanced CBF observed as a result of induced hypertension has been suggested to be dependent on the increase in blood pressure gradient alone $[18,21,24]$. Our data, however, demonstrate a significant dilatation of the narrowed vessels during NE-induced hypertension in an experimental SAH model. Therefore, we suggest that the clinical effect observed is additionally dependent on the dilating effect on the spastic vessel (Fig. 3). The significant increase in vessel diameter, along with the significant increase in blood pressure gradient, may, thus, cause the enhanced CBF and improved clinical outcome observed in the clinical studies during vasopressor-induced hypertension. The mechanism itself of the dilatory effect of NE-induced hypertension on the vessel diameter remains unclear and is subject to further investigation. Hypothetically, a haemodynamic effect might be possible as consequence of direct adrenergic effects on the cerebral vasculature. The pathophysiology of CVS, however, is likely to play a minor role in the dilatory effect observed in our study. The relative dilatory effect of NEinduced hypertension on the BA in SAH animals was merely insignificantly greater than in controls.

Finally, some limitations of this study have to be mentioned. Firstly, the study is limited in providing data about a possible linear relation between blood pressure increase and vasodilatation effect due to single point assessment at high MAP values. Thus, our results are limited in serving for extrapolation to low and very moderate states of induced hypertension. Secondly, our study does not provide data evaluating the consistency over the time of the vasodilatation effects observed; this aspect is subject to further investigation.

\section{Conclusion}

This study demonstrates that NE-induced hypertension therapy significantly dilates the vasospastic basilar artery in a SAH rabbit model. This angiographic finding may possibly serve as an additional explanation for the enhanced CBF and improved clinical outcome observed during vasopressorinduced hypertension therapy in patients suffering from CVS.

Acknowledgments This study was supported by the Cerebrovascular Research Fund from the Departments of Neurosurgery and Intensive Care Medicine (Account Nr. 34-160), University of Bern, and from an unrestricted grant from Actelion Ltd, Allschwil, Switzerland. We are grateful to and thank H.R. Widmer, PhD, J. Schmid, RN, and Mr. H. Rohrer from the Departments of Neurosurgery and Neuroradiology, Bern University Hospital, for their professional laboratory support.

Financial disclosure/Conflict of interest

None of the authors has any conflict of interest to declare.

\section{References}

1. Awad IA, Carter LP, Spetzler RF, Medina M, Williams FC Jr (1987) Clinical vasospasm after subarachnoid haemorrhage: response to hypervolaemic haemodilution and arterial hypertension. Stroke 18:365-372

2. Darby JM, Yonas H, Marks EC, Durham S, Snyder RW, Nemoto EM (1994) Acute cerebral blood flow response to dopamineinduced hypertension after subarachnoid haemorrhage. J Neurosurg 80:857-864

3. Egge A, Waterloo K, Sjoholm H, Solberg T, Ingebrigtsen T, Romner B (2001) Prophylactic hyperdynamic post-operative fluid therapy after aneurysmal subarachnoid haemorrhage: a clinical, prospective, randomised, controlled study. Neurosurgery 49:593-605. discussion 605-596. doi:10.1097/00006123-200109000-00012 
4. Fandino J, Sherman JD, Zuccarello M, Rapoport RM (2003) Cocaine-induced endothelin-1-dependent spasm in rabbit basilar artery in vivo. J Cardiovasc Pharmacol 41:158-161. doi:10.1097/ 00005344-200302000-00002

5. Fergusen S, Macdonald RL (2007) Predictors of cerebral infarction in patients with aneurysmal subarachnoid haemorrhage. Neurosurgery 60:658-667. discussion 667. doi:10.1227/01. NEU.0000255396.23280.31

6. Hoh BS, Ogilvy CS (2002) Risk of haemorrhage from unsecured, unruptured aneurysms during and after hypertensive hypervolaemic therapy. Neurosurgery 50:1207-1211. discussion 1211-1202. doi:10.1097/00006123-200206000-00006

7. Joseph M, Ziadi S, Nates J, Dannenbaum M, Malkoff M (2003) Increases in cardiac output can reverse flow deficits from vasospasm independent of blood pressure: a study using xenon computed tomographic measurement of cerebral blood flow. Neurosurgery 53(Joseph M, Ziadi S, Nates J, Dannenbaum M, Malkoff M):1044-1051 discussion 1051-1042

8. Kassell NF, Peerless SJ, Durward QJ, Beck DW, Drake CG, Adams HP (1982) Treatment of ischaemic deficits from vasospasm with intra-vascular volume expansion and induced arterial hypertension. Neurosurgery 11:337-343. doi:10.1097/00006123198209000-00001

9. Kassell NF, Sasaki T, Colohan AR, Nazar G (1985) Cerebral vasospasm following aneurysmal subarachnoid haemorrhage. Stroke 16:562-572

10. Kosnik EJ, Hunt WE (1976) Post-operative hypertension in the management of patients with intracranial arterial aneurysms. J Neurosurg 45:148-154

11. Lang EW, Diehl RR, Mehdorn HM (2001) Cerebral autoregulation testing after aneurysmal subarachnoid haemorrhage: the phase relationship between arterial blood pressure and cerebral blood flow velocity. Crit Care Med 29:158-163. doi:10.1097/ 00003246-200101000-00031

12. Lee KH, Lukovits T, Friedman JA (2006) “Triple-H” therapy for cerebral vasospasm following subarachnoid haemorrhage. Neurocrit Care 4:68-76. doi:10.1385/NCC:4:1:068

13. Lennihan L, Mayer SA, Fink ME, Beckford A, Paik MC, Zhang H, Wu YC, Klebanoff LM, Raps EC, Solomon RA (2000) Effect of hypervolaemic therapy on cerebral blood flow after subarachnoid haemorrhage : a randomised controlled trial. Stroke 31:383-391

14. Liu-Deryke X, Rhoney DH (2006) Cerebral vasospasm after aneurysmal subarachnoid haemorrhage: an overview of pharmacologic management. Pharmacotherapy 26:182-203. doi:10.1592/ phco.26.2.182

15. Marbacher S, Neuschmelting V, Graupner T, Jakob SM, Fandino J (2008) Prevention of delayed cerebral vasospasm by continuous intrathecal infusion of glyceroltrinitrate and nimodipine in the rabbit model in vivo. Intensive Care Med 34:932-938. doi:10.1007/s00134-008-0995-x

16. Miller JA, Dacey RG Jr, Diringer MN (1995) Safety of hypertensive hypervolaemic therapy with phenylephrine in the treatment of delayed ischaemic deficits after subarachnoid haemorrhage. Stroke 26:2260-2266

17. Muench E, Horn P, Bauhuf C, Roth H, Philipps M, Hermann P, Quintel M, Schmiedek P, Vajkoczy P (2007) Effects of hyper- volaemia and hypertension on regional cerebral blood flow, intracranial pressure, and brain tissue oxygenation after subarachnoid haemorrhage. Crit Care Med 35:1844-1851. quiz 1852. doi:10.1097/01.CCM.0000275392.08410.DD

18. Muizelaar JP, Becker DP (1986) Induced hypertension for the treatment of cerebral ischaemia after subarachnoid haemorrhage. Direct effect on cerebral blood flow. Surg Neurol 25:317-325. doi:10.1016/0090-3019(86) 90205-3

19. Naval NS, Stevens RD, Mirski MA, Bhardwaj A (2006) Controversies in the management of aneurysmal subarachnoid haemorrhage. Crit Care Med 34:511-524. doi:10.1097/01. CCM.0000198331.45998.85

20. Origitano TC, Wascher TM, Reichman OH, Anderson DE (1990) Sustained increased cerebral blood flow with prophylactic hypertensive hypervolaemic haemodilution ("triple- $\mathrm{H}$ " therapy) after subarachnoid haemorrhage. Neurosurgery 27:729-739. discussion 739-740. doi:10.1097/00006123199011000-00010

21. Otsubo H, Takemae T, Inoue T, Kobayashi S, Sugita K (1990) Normovolaemic induced hypertension therapy for cerebral vasospasm after subarachnoid haemorrhage. Acta Neurochir (Wien) 103:18-26. doi:10.1007/BF01420187

22. Pluta RM (2005) Delayed cerebral vasospasm and nitric oxide: review, new hypothesis, and proposed treatment. Pharmacol Ther 105:23-56. doi:10.1016/j.pharmthera.2004.10.002

23. Raabe A, Beck J, Keller M, Vatter H, Zimmermann M, Seifert V (2005) Relative importance of hypertension compared with hypervolaemia for increasing cerebral oxygenation in patients with cerebral vasospasm after subarachnoid haemorrhage. J Neurosurg 103:974-981

24. Sen J, Belli A, Albon H, Morgan L, Petzold A, Kitchen N (2003) Triple-H therapy in the management of aneurysmal subarachnoid haemorrhage. Lancet Neurol 2:614-621. doi:10.1016/S1474-4422 (03) 00531-3

25. Soehle M, Czosnyka M, Pickard JD, Kirkpatrick PJ (2004) Continuous assessment of cerebral auto-regulation in subarachnoid haemorrhage. Anesth Analg 98:1133-1139. table of contents. doi:10.1213/01.ANE.0000111101.41190.99

26. Solomon RA, Fink ME, Lennihan L (1988) Early aneurysm surgery and prophylactic hypervolaemic hypertensive therapy for the treatment of aneurysmal subarachnoid haemorrhage. Neurosurgery 23:699-704

27. Suzuki M, Asahara H, Endo S, Inada K, Doi M, Kuroda K, Ogawa A (1999) Increased levels of nitrite/nitrate in the cerebrospinal fluid of patients with subarachnoid haemorrhage. Neurosurg Rev 22:96-98. doi:10.1007/s101430050038

28. Treggiari MM, Walder B, Suter PM, Romand JA (2003) Systematic review of the prevention of delayed ischaemic neurological deficits with hypertension, hypervolaemia, and haemodilution therapy following subarachnoid haemorrhage. J Neurosurg 98:978-984

29. Yano K, Kuroda T, Tanabe Y, Yamada H (1993) Preventive therapy against delayed cerebral ischaemia after aneurysmal subarachnoid haemorrhage: trials of thromboxane A2 synthetase inhibitor and hyperdynamic therapy. Acta Neurochir (Wien) 125:15-19. doi:10.1007/BF01401822 